Lee J.H., Kim H. S., Lee E. and Lee S.Y. (2020). "Development of AI-based engineering Big Data integrated analysis system for decision-making support in the Engineering-Procurement-Construction (EPC) industry" In: Proc. 37th CIB W78 Information Technology for Construction Conference (CIB W78), São Paulo, Brazil, pp. 58-68. DOI: http://dx.doi.org/10.46421/2706-6568.37.2020.paper005

\title{
DEVELOPMENT OF AI-BASED ENGINEERING BIG DATA INTEGRATED ANALYSIS SYSTEM FOR DECISION-MAKING SUPPORT IN THE ENGINEERING- PROCUREMENT-CONSTRUCTION (EPC) INDUSTRY
}

\author{
Jung Hyun. Lee ${ }^{1}$, Hyun Soo. Kim ${ }^{2}$, Eul-bum. Lee ${ }^{3}$ and Seung Yeab. Lee ${ }^{4}$
}

\begin{abstract}
Plant Engineering-Procurement-Construction (EPC) industry is one of the complex industries going through various stages from bidding to engineering, construction and operation and maintenance (O\&M). A systematic management system is needed to address these complexities. However, many EPC companies in Korea are having difficulty managing their projects due to the lack of data-based systematic decision-making, and are suffering heavy losses in overseas projects.
\end{abstract}

The AI-based engineering big data integrated analysis system proposed by this study aims to minimize project losses and eventually to enhance the technical skills and competitiveness of the Korean plant industry through decision-making support, combining big data and AI in the entire EPC project life cycle. In this study, knowledge base was established to utilize various data generated during the entire EPC project life cycle in AI-based engineering big data integrated analysis systems. And a machine learning integrated platform specialized in the engineering industry was developed to support feature engineering, model learning and model operation processes. Using various algorithms from the machine learning integration platform and the knowledge base, five main decision-making applications were developed: analyzing bidding documents, predicting design costs, analyzing design errors, analyzing change order, and plant equipment prediction maintenance.

Based on the predicted information, the system could help EPC project managers identify and manage risks at each stage of the project in advance to make decisions that minimize project loss. Furthermore, the information predicted at each stage may be circulated or used as feedback for decision making at other stages.

Keywords: Plant Project, Engineering, Construction Lifecycle, Smart Decisionmaking support system, Big-Data, Artificial Intelligence.

\section{INTRODUCTION}

The plant industry is made up of large, complex industries having various phases, ranging from bidding to engineering, construction, operation and maintenance, as well

1 Graduate Student, Pohang University of Science and Technology(Postech), Pohang, Korea, leejunghyun@postech.ac.kr

2 Chief Researcher, Sangah Management Consulting co., Seoul, Korea, hskim@sangah.com

3 Professor, Pohang University of Science and Technology(Postech), Pohang, Korea, dreblee@postech.ac.kr

4 Chief Researcher, Pohang University of Science and Technology(Postech), Pohang, Korea, sylee7@postech.ac.kr 
as high-tech manufacturing technologies, and technology-intensive industries that require knowledge services such as design, production and finance.

However, many EPC companies are having difficulties in Life-cycle construction management because they do not have a data-based, systematic decision-making system such as a track record. In addition, insufficient management of unknown risks such as Country Risk and Schedule Risk often results in losses in construction.

In addition, in order for Korean EPC companies to survive the competition with major global EPC companies, it is imperative to secure competitiveness against plant value chains, including high value upstream parts such as Project Management Consultancy (PMC) and Front-End Engineering Design (FEED).

Therefore, in order to lay the foundation for securing the competitiveness of the Korean plant industry, we suggest AI-based engineering big data integrated analysis system technology that enables optimal decision making and execution in the pre-plant cycle process so that Korean EPC companies could predict and respond to risks in the bidding, execution, construction and maintenance phases of the project in advance.

To support decision-making by project stage, the research team built a knowledge base ranging from ITB (Invitation to Bid, bid document) analysis at the bidding stage to plant facility forecast maintenance of the O\&M stage, select-ed features, and combined algorithms of machine learning platforms to create a machine learning solution.

The following Table 1 shows the five modules of this engineering decision-making technology development.

Table 1: Summary of five study parts.

\begin{tabular}{|c|c|c|}
\hline Project Stage & Module & Contents \\
\hline Bidding & $\begin{array}{l}\text { Engineering design cost } \\
\text { prediction }\end{array}$ & $\begin{array}{l}\text { Analysing past engineering design man-hour } \\
\text { and cost to predict accurate engineering design } \\
\text { man-hour of new project }\end{array}$ \\
\hline Bidding & $\begin{array}{l}\text { Engineering ITB } \\
\text { analysis }\end{array}$ & $\begin{array}{c}\text { Establish bidding strategy through analysis of } \\
\text { con-tract key issues and respond to risks through } \\
\text { analysis of risk clause }\end{array}$ \\
\hline Engineering & $\begin{array}{l}\text { Engineering Design } \\
\text { Error Analysis }\end{array}$ & $\begin{array}{l}\text { Analysis of design error report (crash, missing } \\
\text { report) information to provide proactive design } \\
\text { risks and types of equipment and equipment with } \\
\text { high potential for design delay and error }\end{array}$ \\
\hline $\begin{array}{l}\text { Engineering } \\
\text { \&Construction }\end{array}$ & $\begin{array}{l}\text { Engineering Change } \\
\text { Order Analysis }\end{array}$ & $\begin{array}{l}\text { Analyse the causes of design changes and pre- } \\
\text { sent risk impact and trend by types, and provide } \\
\text { information that can be reflected in contract, } \\
\text { design, purchase, and construction work. }\end{array}$ \\
\hline $\begin{array}{c}\text { Operation } \\
\text { \&Maintenance }\end{array}$ & $\begin{array}{c}\text { Plant Equipment } \\
\text { Predictive Maintenance }\end{array}$ & $\begin{array}{l}\text { Predict maintenance items for major plant } \\
\text { facilities }\end{array}$ \\
\hline
\end{tabular}

In addition to introducing the above five key decision support modules in Section 3, this Paper will cover one of the decision support modules in Section 4 in more detail. 
Development of AI-based engineering Big Data integrated analysis system for decision-making support in the Engineering-Procurement-Construction (EPC) industry

\section{LITERATURE REVIEW}

In recent years, the construction industry has become more complex, and the need for advanced project management is increasing. As a result, there are a growing number of cases and studies that apply big data, AI, and machine learning algorithms to the construction industry. [1] James. $\mathrm{D}(2005)$ of AACE present-ed a correlation and prediction study between equipment and plant engineering design man-hours using regression analysis. [2] Mohamed Marzouk(2016) developed a water treatment plant construction estimating model using the Artificial Neutral Network Method in 2016. [3]Sphurti S. Arage (2017) and [4] Igor Pesko (2017) developed a Civil Construction Cost Estimation model by applying machine learning algorithms in their respective studies.

However, compared to other industries, the plant industry is relatively slow in applying machine learning and quantitative statistical analysis. In particular, researches for predicting plant engineering design man-hours are not actively con-ducted, and each EPC company or Engineering company adheres to the tradition-al method of estimating and calculating quantities. Therefore, this study intends to present engineering design man-hour prediction model after collecting historical data and performing quantitative analysis.

\section{FIVE DECISION SUPPORT MODULES INTRODUCTION}

As mentioned above, this study consists of five modules, such as engineering design cost prediction, engineering design error analysis, engineering design change analysis, engineering ITB analysis, and plant facility forecasting maintenance, and this section provides a summary of the objectives and development methods of these five modules.

\subsection{Engineering Design Cost Prediction}

Estimating design costs is the work performed in the initial bidding phase of the project and has a great impact on the decision making of the project participants. EPC Company or Engineering Company shall estimate accurate design costs and reflect them in the schedule and expense plan before embarking on plant design work. However, since there is limited information available at the beginning of the project, qualitative factors such as the experience of the engineers in charge are often reflected, and hence the accuracy of the estimate has been often less accurate. Thus, this research team collected about 40 past EPC plant project data consisting of drawing list, equipment list and project information, etc. and con-ducted analysis from a big data perspective. As a result, a model was developed to estimate the engineering design man-hour using information from the beginning of the project, and a function was implemented to select and provide useful reference data to project participants.

\subsection{Engineering Design Error Analysis}

In plant projects, where a large amount of complex design is executed in a short period of time, design errors and omissions often occur. These design errors and omissions are one of the main risk factors that cause schedule delay, cost in-creases, and quality degradation during the subsequent construction phase, and not just during the design phase. Therefore, in this module after collecting historical plant project data, we developed an automatic classification system of design errors and an algorithm to predict the risks from the cost aspects of each type in order to minimize a project risk due to design errors by utilizing big data statistical analysis and machine learning. 


\subsection{Engineering Change Order Analysis}

Due to the nature of long-running plant projects, design changes are often caused by internal causes of the project, such as scope, function and use, and by external factors such as political, economic and environmental changes. However, it is not uncommon for compensation from owners for delays and increases in costs caused by design changes to be paid improperly. And this leads to a loss to project participants. Therefore, this module developed a design change type automatic classification system and severity prediction algorithm by classifying de-sign changes by type and calculating the severity by type based on historical data so that users can proactively recognize and cope with the risks of design changes occurring.

\subsection{Engineering ITB Analysis}

The bidding phase of a plant project is a very important period for project participants. Early detection of potential risk conditions on bid documents and prevention of losses is a prerequisite for successful project execution within a limited period of time, and is generally required by a large number of experts in each field. In this module, the NLP(Natural Language Process) and text-mining technology, and machine learning are used to prepare systematic procedures for the extraction of risk clauses on bid documents, and to automate tasks to enable more objective and quick review of bid documents.

\subsection{Plant Equipment Predictive Maintenance}

Ensuring the stability of plant facility system operation is of paramount importance to prevent major accidents. Although preventive maintenance and parts replacement are carried out regularly to prevent the failure of the facility system, such existing methods are limited in preventing the sudden failure. Therefore, to minimize the loss of plant operators, this study developed a technique for predicting equipment failure by using anomaly detection and machine learning techniques. By using the developed prediction algorithm, accurate pre-diagnosis can reduce unnecessary maintenance costs, increase the stability and reliability of the system, and prevent system failures and accidents.

\section{ENGINEERING DESIGN COST PREDICTION}

This section dwells on the design cost prediction module, one of the five modules introduced above. The purpose of this study is to identify the correlation between information (Basic Drawing list, Equipment list, Line list, etc.) that can be used in the initial bidding stage of a project and actual design man-hour, and to create a prediction model.

The collected drawing list was reclassified into 27 design activities using SMEs, and Unit man-hour was calculated for each activity. Then, the design man-hour trend was analysed according to the project country, duration, and scale. User can calculate the general design man-hour by inputting the required quantity based on the 27 design activity lists. The developed correction factor can be used to increase the accuracy of the estimate according to the characteristics of the user project. In addition, a similar project recommendation function using the CBR technique was implemented. The step-by-step flow is summarized in Figure 1 below, and each of these steps is described in detail in the following sections. 
Development of AI-based engineering Big Data integrated analysis system for decision-making support in the Engineering-Procurement-Construction (EPC) industry

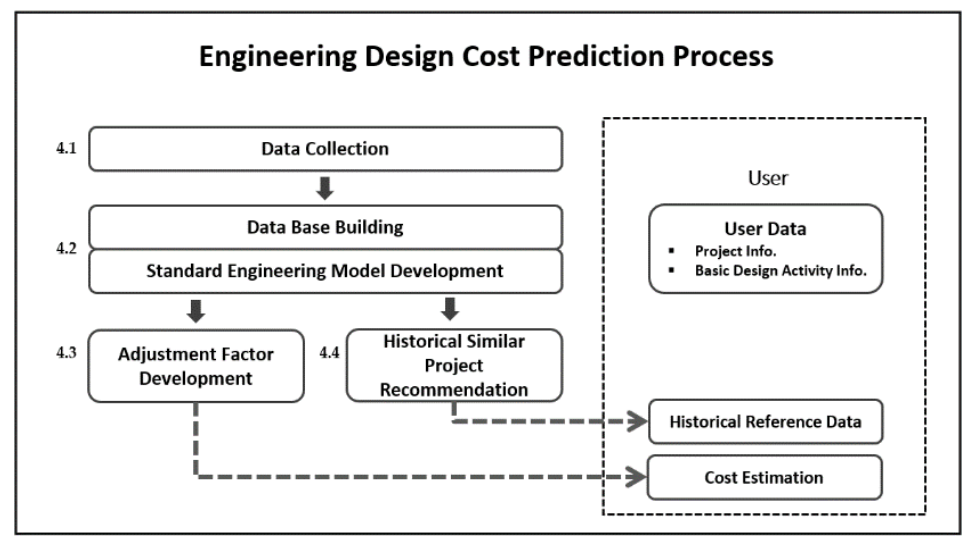

Fig. 1: Engineering design man-hour prediction algorithm development flow

\subsection{Data Collection}

Many historical plant project data have been collected.

This section introduces historical plant project data collected from project participants. In particular, this study focused on collecting and analysing data related to piping design, which takes up 40-50\% man-hour of the plant's overall design work volume and $25-34 \%$ of the total construction cost of the plant. Data from 40 projects comprising drawing list, equipment list, and project information were collected.(Figure

2,3 below).

\begin{tabular}{|c|c|c|c|c|c|c|c|c|c|c|c|}
\hline \multicolumn{12}{|c|}{ A Project } \\
\hline \multirow[b]{2}{*}{ 공종 } & WBS & & Drawing & $\frac{2}{5}$ & & \multicolumn{6}{|c|}{ Completion Percentage of Stage(Plan) } \\
\hline & WBSCODE & DWG No. & DWG Title & हुँ & Manhour & Step 1 & Step 2 & Step 3 & Step 4 & \begin{tabular}{|l|} 
Step 5 \\
\end{tabular} & Step 6 \\
\hline & & & & & & $\begin{array}{lll}\text { START } \\
(0 \%)\end{array}$ & $\begin{array}{c}\text { stuor } \\
(5 \%)\end{array}$ & $\begin{array}{c}\text { DRAFT } \\
(10 \%)\end{array}$ & $\left.\begin{array}{c}\text { IFR } \\
(30 \%)\end{array}\right)$ & $\begin{array}{c}\mathrm{IFC} \\
(\mathrm{s} 5 \%)\end{array}$ & \\
\hline \multirow[t]{2}{*}{ PR } & AOEAOPPR0202501 & U00-K- -0221-RP & WASTE DISPOSAL REPORT & A & 71 & 2012-11-01 & $2012-11-06$ & $2012-12-24$ & $2012-12-3$ & $\frac{\mid 013-02-28}{2013} \mid$ & $2013-04-16$ \\
\hline & & & & & & \begin{tabular}{|c|c|c|} 
SART \\
$\left(0_{0}\right)$
\end{tabular} & \begin{tabular}{|c|c|c|} 
stuor \\
$(55 \%)$
\end{tabular} & \begin{tabular}{|l|l} 
DRAFT \\
(10\%
\end{tabular} & $\begin{array}{lll}\text { IFR } \\
(10 \%)\end{array}$ & \begin{tabular}{c|cc}
$\mathrm{IFD}$ \\
$(15 \%)$
\end{tabular} & AFD \\
\hline \multirow[t]{2}{*}{ PR } & POEAOPROO200601 & $000-K-0026-5 A$ & OFERAT TNG WINOOWS AND SAFE OPERATTNG ENVELOPS & A & 72 & $2012-11-30$ & $2012-12-05$ & 2013-10-04 & $2013-10-2$ & $2013-12-20$ & $2014-01-31$ \\
\hline & & & & & & START & studY & DRAFT & IFR & IIIC & \\
\hline \multirow[t]{2}{*}{ PR } & AOEAOPRO0200801 & AOEAOPPR0020801 & OPTIMEATION STUDIES \& EVALLATION REPORT & $\mathrm{R}$ & 70 & $2013-08-01$ & $20013-08-15$ & $\mid 2013-10-31$ & $2013-11-15$ & $5=2014-01-16$ & \\
\hline & & & & & & \begin{tabular}{|l} 
STAAT \\
$(0 \%)$
\end{tabular} & \begin{tabular}{|c|c|} 
I1F \\
$(100 \%)$
\end{tabular} & & & & \\
\hline \multirow[b]{3}{*}{ 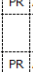 } & AOEAAPRO020091 & U00-K-0025-PR & VENDOR INFORMATION ON PACACAEE UNITS & $\mathrm{I}$ & 67) & $2013-07-01$ & $\mid 2013-09-30$ & & & & \\
\hline & & & & & & \begin{tabular}{|l|l} 
START \\
S(0)
\end{tabular} & \begin{tabular}{|c|c|c|} 
stuov \\
(5\%)
\end{tabular} & DRAFT & IFR & IFC & \\
\hline & AOEAOPRO021001 & U00-K-0023-PD & ALARM \& TRPP VALUES & R & 374 & $\frac{100}{2013-07-01}$ & $\begin{array}{ll}-5013-07-09 \\
209\end{array}$ & $\frac{1000}{2013-09-25}$ & $\frac{(1000)}{2013-10-27}$ & $\frac{135 \%}{2013-12-31}$ & \\
\hline & & & & & & START & stuov & DRAFT & IFR & 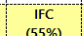 & \\
\hline
\end{tabular}

Fig. 2: Drawing List Sample

INFORMATION \& VENDOR PRINT STATUS

\begin{tabular}{|c|c|c|c|c|c|c|c|c|c|c|c|}
\hline \multirow{3}{*}{$\begin{array}{l}\text { UNIT } \\
\text { Unit A }\end{array}$} & \multirow{3}{*}{$\frac{\text { ITEM NO. } 1}{\text { C-74101 }}$} & \multirow{2}{*}{\multicolumn{3}{|c|}{ ITEM NO. 2}} & \multirow{3}{*}{$\begin{array}{c}\text { DESCRIP TION } \\
\text { RECYCLE COMPRESSOR }\end{array}$} & \multirow{3}{*}{$\begin{array}{l}\text { EQUIPMENT } \\
\text { TYPE }\end{array}$} & \multirow{3}{*}{$\frac{\text { aTY }}{1}$} & \multicolumn{4}{|c|}{ DATASHEET } \\
\hline & & & & & & & & \multirow{2}{*}{$\begin{array}{l}\text { REV. } \\
\text { BO }\end{array}$} & \multirow{2}{*}{$\begin{array}{l}\text { RECEIVED } \\
2008.01 .30\end{array}$} & \multicolumn{2}{|c|}{ DIMENSION FOR NOZZLE } \\
\hline & & c & 74101 & & & & & & & & 0 \\
\hline Unit $A$ & C-74102A/B & c & 74102 & $A \sqrt{B}$ & MAKE-UP COMPRESSOR & COMPRESSOR & 2 & B1 & 2009.06 .01 & & 0 \\
\hline Unit $A$ & C-74201 & c & 74201 & & RECYCLE COMPRESSOR & COMPRESSOR & 1 & Bo & 200801.30 & & 0 \\
\hline Unit $A$ & C.74202 & c & 74202 & & MAKE-UP COMPRESSOR & COMPRESSOR & 1 & B1 & 2009.06 .01 & & 0 \\
\hline Unit $A$ & C-74401 & c & 74401 & & RECIRCULATION COMPRESSOR & COMPRESSOR & 1 & B1 & 2009.06 .01 & & 0 \\
\hline Unit $A$ & DS-74301 & DS & 74301 & & MP STEAM DESUPERHEATER & MISCELLANEOUS & 1 & B1 & 2010.0122 & & 0 \\
\hline Unit $A$ & DS-74302 & DS & 74302 & & STRIPPER DESUPREHEATER & MISCELLANEOUS & 1 & B1 & 2010.01 .22 & & 0 \\
\hline Unit $A$ & DS- -74303 & os & 74303 & & LP STEAM DESUPERHEATER & MISCELLANEOUS & 1 & B1 & 2010.0122 & & 0 \\
\hline
\end{tabular}


Fig. 3: Equipment List Sample

\subsection{Standard Master Drawing Register for piping development and data standardization}

\subsubsection{Standard Master Drawing Register (SMDR)}

Standard Master Drawing Register (SMDR) was developed and the collected data was standardized.

Drawing lists of the collected projects were reorganized to the same standards in collaboration with plant engineers with more than 20 years of experience. And database was built (Table 2 below). Based on the unit man-hours of drawing list of each project, the average value for each of the 27 standardized design activities was calculated as the standard unit man-hour. Table 2 below shows 27 design activity lists and unit man-hours.

Table 2: SMDR (Standard Master Drawing Register)

\begin{tabular}{|c|c|c|}
\hline No. & Design Activity List & Unit Man-hour(hours) \\
\hline 1 & Line list \& Tie in List & 123 \\
\hline 2 & Piping Information drawing & 215 \\
\hline 3 & Vendor Print Review \& Data sheet & 499 \\
\hline 4 & UFD \& PNID Review & 91 \\
\hline 5 & Plot Plan \& Equipment Arrangement drawing & 91 \\
\hline 6 & Utility Station \& Safety Shower Location Plan & 18 \\
\hline 7 & Steam Tracing Diagram & 28 \\
\hline 8 & Tracing Circuit drawing & 4 \\
\hline 9 & Stress Geometry drawing & 4 \\
\hline 10 & Pulsation Study Diagram & 45 \\
\hline 11 & B/M Sketch drawing \& MTO with key Punch & 2 \\
\hline 12 & Key plan drawing. & 17 \\
\hline 13 & Standard \& Special Support Detail drawing & 4 \\
\hline 14 & Stress Geometry drawing & 4 \\
\hline 15 & Stress analysis_Specialty item data sheet for stress & 5 \\
\hline 16 & Stress analysis_Piping Flexibility analysis_Critical & 239 \\
\hline 17 & Stress analysis_Piping Flexibility analysis_Non Critical & 162 \\
\hline 18 & Stress analysis_AIV\&FIV analysis $\&$ report & 97 \\
\hline 19 & Conceptual Piping Design_Process Area & 76 \\
\hline 20 & Conceptual Piping Design_P/R \& Off site area & 60 \\
\hline 21 & Conceptual Piping Design_U/G area & 23 \\
\hline 22 & PDMS Modeling(Equipment) & 55 \\
\hline 23 & PDMS Modeling(Layout) & 207 \\
\hline
\end{tabular}


Development of AI-based engineering Big Data integrated analysis system for decision-making support in the Engineering-Procurement-Construction (EPC) industry

24

25

26

27
PDMS Model Review

ISO drawing \& BM Generation

3D Piping plan drawing Generation

Piping Engineering follow up(INCL. AS Built)
80

2

13

450

\subsubsection{Data Standardization}

The collected data was standardized in the same form.

For the convenience of comparison and analysis, all project data were converted as follows. The period was calculated on a monthly basis and the project areas were classified into Korea, Middle East Asia, and Southeast Asia. Project scales (project cost) were converted to Dollar in 2019 using the CPI(Consumer Price Index). In the case of the equipment list, information on the quantity of equipment considered to affect the design time was calculated. The Fig 4 below show the standardized data set form.

\begin{tabular}{|c|c|c|c|c|c|c|c|c|c|c|}
\hline \multicolumn{2}{|r|}{$\frac{\text { Paht El }}{\text { Project Number }}$} & \multicolumn{3}{|c|}{1} & \multicolumn{3}{|c|}{2} & \multicolumn{3}{|c|}{3} \\
\hline & Project Name & \multicolumn{3}{|c|}{ Project A } & \multicolumn{3}{|c|}{ Project B } & \multicolumn{3}{|c|}{ Project C } \\
\hline & Onshore / Off shore & \multicolumn{3}{|c|}{ Onshore } & \multicolumn{3}{|c|}{ Onshore } & \\
\hline & Plant Type & \multicolumn{3}{|c|}{ refinery } & \multicolumn{3}{|c|}{ refinery } & \multicolumn{3}{|c|}{ Chemical } \\
\hline & Contractor & \multicolumn{3}{|c|}{ D EPC Company } & \multicolumn{3}{|c|}{ D EPC Company } & \multicolumn{3}{|c|}{ D EPC Company } \\
\hline & Owner & \multicolumn{3}{|c|}{ S Owner Company } & \multicolumn{3}{|c|}{ E Owner Company } & \multicolumn{3}{|c|}{ E Owner Company } \\
\hline & Country & \multicolumn{3}{|c|}{ Korea } & \multicolumn{3}{|c|}{ Middle East Asia (Iran) } & \multirow{2}{*}{\multicolumn{3}{|c|}{$\begin{array}{l}\text { Middle East Asia (Iran) } \\
\qquad 16\end{array}$}} \\
\hline & Project Duration (Months) & \multirow{4}{*}{\multicolumn{3}{|c|}{$\begin{array}{c}27 \\
20768120 \\
163 \\
11110\end{array}$}} & \multirow{4}{*}{\multicolumn{3}{|c|}{$\begin{array}{c}38 \\
15175656 \\
63 \\
666\end{array}$}} & & & \\
\hline & Project Scale (Dollar) & & & & & & & & 590191 & \\
\hline & Equipment Quantity & & & & & & & & 21 & \\
\hline & Piping Line Quantity & & & & & & & & 473 & \\
\hline No. & Standard Drawing List for Piping & Unit $\mathrm{MH}$ & Q'ty & Total MH & Unit MH & Q'ty & Total $\mathrm{MH}$ & Unit MH & $Q^{\prime}$ ty & Total $\mathrm{MH}$ \\
\hline 1 & Line list \& Tie in List & 168 & 1 & 168 & 55 & 1 & 55 & 23 & 1 & 23 \\
\hline 2 & Piping Information drawing & 337 & 1 & 337 & 109 & 1 & 109 & 45 & 1 & 45 \\
\hline 3 & Vendor Print Review \& Comments & 1,010 & 1 & 1.010 & 328 & 1 & 328 & 136 & 1 & 136 \\
\hline 4 & UFD \& PNID Review & 100 & 1 & 100 & 100 & 1 & 100 & 100 & 1 & 100 \\
\hline 5 & Plot Plan \& Equipment Arrg't drawing & 95 & 7 & 665 & 95 & 2 & 190 & 95 & 2 & 190 \\
\hline 6 & Utility Station \& Safety Shower Loaction Plan & 20 & 3 & 50 & 19 & 2 & 38 & 19 & 1 & 19 \\
\hline 7 & Steam Tracing Diagram & 30 & 2 & 50 & 29 & 1 & 29 & 29 & 1 & 29 \\
\hline 8 & Tracing Curcuit Drawing & 2 & 90 & 180 & 2 & 91 & 181 & 2 & 220 & 524 \\
\hline 9 & Stress Geometry drawing & 4 & 280 & 1.067 & 4 & 420 & 1,596 & 4 & 220 & 836 \\
\hline 10 & Pulsation Study Diagram & 40 & 23 & 900 & 48 & 20 & 950 & 48 & 20 & 950 \\
\hline 11 & B/M Sketch dwg. \& MTO with key Punch & 1 & 4,500 & 5,130 & 1 & 2,000 & 2,000 & 1 & 225 & 257 \\
\hline 12 & Key plan dwg.(2D New \& Exist) & 40 & 1 & 40 & 10 & 1 & 10 & 10 & 1 & 10 \\
\hline 13 & Standard \& Special Support Detall drawing & 4 & 30 & 120 & 4 & 30 & 120 & 4 & 30 & 120 \\
\hline 14 & Stress Geometry drawing & 4 & 300 & 1,200 & 4 & 300 & 1,200 & 4 & 300 & 1,200 \\
\hline 15 & Stress analysis _ Specialty item data sheet for stress & 4 & 35 & 140 & 5 & 30 & 143 & 5 & 30 & 143 \\
\hline 16 & Stress analysis_Piping Flexbiity analysis_critical & 23 & 210 & 4,828 & 20 & 225 & 4,500 & 20 & 225 & 4,500 \\
\hline 17 & Stress analysis_Piping Flexbility analysis_Non Critical & 19 & 185 & 3,480 & 15 & 200 & 3,000 & 15 & 200 & 3,000 \\
\hline 18 & Strss analysis_AIV\&\&IV anaysis \& report & 100 & 1 & 100 & 100 & 1 & 100 & 100 & 1 & 100 \\
\hline 19 & Conceptual Piping Design_Preocess Area & 81 & 35 & 2,826 & 81 & 6 & 485 & 81 & 2 & 162 \\
\hline 20 & Conceptual Piping Design_P/R \& Off site area & 52 & 25 & 1,306 & 52 & 3 & 157 & 52 & 1 & 52 \\
\hline 21 & Conceptual Piping Design_U/G area & 24 & 1 & 24 & 24 & 1 & 24 & 24 & 1 & 24 \\
\hline 22 & PDDSS Modeling(Equipment) & 42 & 19 & 820 & 36 & 1 & 36 & 35 & 1 & 35 \\
\hline 23 & PDMS Modeling(Layout) & & & & & & & & & \\
\hline 24 & PDMS Model Review & 25 & 257 & 6,347 & 214 & 29 & 6,195 & 215 & 6 & 1,290 \\
\hline 25 & ISO Dwg. \& BM Generation & 150 & 1 & 150 & 150 & 1 & 150 & 150 & 1 & 150 \\
\hline 26 & 3D Piping plan drawing Geneation & 250 & 1 & 250 & 250 & 1 & 250 & 250 & 1 & 250 \\
\hline 27 & Piping Engineering follow up(INCL. AS Built) & 400 & 1 & 400 & 400 & 1 & 400 & 400 & 1 & 400 \\
\hline & Total & 3,025 & 10 & 31,688 & 2,154 & 10 & 22,345 & 1,866 & 8 & 14,543 \\
\hline
\end{tabular}

Fig. 4: Standardized data set example

\subsection{Adjustment Factor Development}

Adjustment factors were developed to reflect trends in design man-hour according to project characteristic information. After setting the project characteristic classification 
criteria (Table 3) through the SME(Subject Matter Expert)s survey technique, the factor was calculated by comparing relative increments and reductions.

Currently, the country factor, period factor, and scale factor have been developed, and detailed development methods are as follow. User can apply by multiplying each factor according to the user's project condition by the standard de-sign man hour value calculated using the SMDR of 4.2section

Table 3: Project Characteristic Classification Criteria

\begin{tabular}{|c|c|c|}
\hline Adjustment Factors & \multicolumn{2}{|c|}{ Classification } \\
\hline \multirow[t]{3}{*}{ Country } & Korea (Standard) & Korea \\
\hline & Middle East Asia & Malaysia \\
\hline & Southeast Asia & $\begin{array}{l}\text { Saudi Arabia } \\
\text { Iran }\end{array}$ \\
\hline \multirow[t]{4}{*}{ Duration } & \multicolumn{2}{|c|}{0 - 12 months } \\
\hline & \multicolumn{2}{|c|}{13 - 24 months (Standard) } \\
\hline & \multicolumn{2}{|c|}{25 - 36 months } \\
\hline & \multicolumn{2}{|c|}{37 - 48 months } \\
\hline \multirow[t]{4}{*}{ Scale } & \multicolumn{2}{|c|}{ Less than $\$ 1$ million } \\
\hline & \multicolumn{2}{|c|}{$\begin{array}{l}\text { More than } \$ 1 \text { million and less than } \$ 4 \text { million } \\
\text { (Standard) }\end{array}$} \\
\hline & \multicolumn{2}{|c|}{ More than $\$ 4$ million and less than $\$ 6$ million } \\
\hline & \multicolumn{2}{|c|}{ More than $\$ 6$ million } \\
\hline
\end{tabular}

\subsubsection{Country Factor}

The country factor was developed to reflect the design man-hour change by country condition. An engineering man-hour prediction regression model was developed for 20 projects conducted in Korea. After that, the characteristic information variables of other country project were inputted into the Korean project regression prediction model, and the increase/decrease rate was regarded as a difference according to the country of the project. The regression model for Korea Project results and developed factors are shown in Table 4 below.

Table 4: Summary of Korea Project Regression Model and Country Factor

\begin{tabular}{cccccc}
\hline \multicolumn{2}{c}{ Regression Model for Korea Project } & \multicolumn{3}{c}{ Country Factor } \\
\hline \multirow{2}{*}{ MAPE $(\%)$} & R-squared & P-value & Korea & Middle East & Southeast \\
\multirow{2}{*}{11.41} & 0.94 & $1.042 \times 10^{-8}$ & 1.0 & Asia & Asia \\
\hline
\end{tabular}

\subsubsection{Duration Factor}

Similar to the above method, we created a regression model that predicts man-hours for projects ranging from 13 to 24 months. And design man-hour was predicted by 
Development of AI-based engineering Big Data integrated analysis system for decision-making support in the Engineering-Procurement-Construction (EPC) industry

inputting variables of different period groups. Like the Country Factor, the difference between the predicted and actual values was considered to be due to the duration of the project. The regression result and developed factors are summarized in the table 5 below.

Table 5: Summary of Normal Duration Project Regression Model and Duration Factor

\begin{tabular}{ccccccc}
\hline \multicolumn{2}{c}{ Regression Model Normal Duration } & \multicolumn{5}{c}{ Duration Factor } \\
\hline \multicolumn{3}{c}{ Project } \\
MAPE $(\%)$ & R-squared & P-value & $0-12$ & $13-24$ & $25-36$ & $37-48$ \\
& & & months & months & months & months \\
19.40 & 0.87 & $2.867 \times 10^{-5}$ & 0.93 & 1.0 & 1.13 & 1.35 \\
\hline
\end{tabular}

\subsubsection{Scale Factor}

Scale factors have also been developed similar to the above method. After generating a man-hour prediction regression model with a project of the general scale, the design man-hour was estimated using small-scale and large-scale data as in-put variables. The difference between the design man-hour value and the actual value of the two project scale groups predicted by the model was considered to be due to the tendency to follow the group. The regression model result and developed factors are shown in Table6 below.

Table 6: Summary of Normal Scale Project Regression Model and Scale Factor

\begin{tabular}{|c|c|c|c|c|c|c|}
\hline \multicolumn{3}{|c|}{$\begin{array}{c}\text { Regression Model for Normal Scale } \\
\text { Project }\end{array}$} & \multicolumn{4}{|c|}{ Scale Factor } \\
\hline MAPE(\%) & R-squared & P-value & $\begin{array}{c}\text { Less than } \\
\quad \$ 1 \\
\text { million }\end{array}$ & $\begin{array}{c}\text { More than } \\
\$ 1 \\
\text { million } \\
\text { and less } \\
\text { than } \$ 4 \\
\text { million }\end{array}$ & $\begin{array}{l}\text { More than } \\
\$ 4 \text { million } \\
\text { and less } \\
\text { than } \$ 6 \\
\text { million }\end{array}$ & $\begin{array}{c}\text { More } \\
\text { than } \\
\$ 6 \\
\text { million }\end{array}$ \\
\hline 12.87 & 0.90 & $7.189 \times 10^{-6}$ & 0.83 & 1.20 & 1.17 & 1.37 \\
\hline
\end{tabular}

\subsection{Historical Similar Project Recommendation}

In addition, similar project suggestion function using CBR method has been developed. CBR method is a technique that finds the most similar cases among past cases and uses that for problem solving. In this study, the priority of each factor in judging project similarity was investigated through SME questionnaire. These factors refer to the standardized project data set introduced in section 4.2. The survey results of SME were used to establish similar project selection criteria and the criteria in-formation is shown in Table 7 below. 
Table 7: Similar Project Selection Criteria and Survey Result

\begin{tabular}{ccccccc}
\hline SME & $\begin{array}{c}\text { Result } \\
\# 1\end{array}$ & $\begin{array}{c}\text { Result } \\
\# 2\end{array}$ & $\begin{array}{c}\text { Result } \\
\# 3\end{array}$ & $\begin{array}{c}\text { Result } \\
\# 4\end{array}$ & $\begin{array}{c}\text { Result } \\
\# 5\end{array}$ & $\begin{array}{c}\text { Weight Factor for each } \\
\text { characteristic } \\
\text { (Average Value of } \\
\text { distributed points) }\end{array}$ \\
\hline $\begin{array}{c}\text { On shore/ } \\
\text { Off shore }\end{array}$ & 35 & 25 & 30 & 30 & 30 & 30 \\
Project & 20 & 25 & 20 & 20 & 15 & 20 \\
Country & & 20 & 25 & 15 & 20 & 20 \\
$\begin{array}{c}\text { Plant Type } \\
\text { Project }\end{array}$ & 15 & 10 & 10 & 5 & 10 & 10 \\
Duration & 15 & 10 & 10 & 15 & 10 & 10 \\
$\begin{array}{c}\text { Scale Total } \\
\text { Equipment }\end{array}$ & 5 & 10 & 5 & 15 & 15 & 10 \\
Quantity & 5 & & & & & \\
\hline
\end{tabular}

When the user enters a project information variable, the similarity score is calculated by the designed similar project selection criteria. The three projects with the highest scores are selected and provided with basic information such as plant type, duration and scale, and details such as plumbing drawings and man-hour information.

\section{CONCLUSION}

In this study, a man-hour prediction algorithm and tool for plant piping design was developed. The development process is as follows.

Step 1. Data collection: About 40 historical plant project data were collected.

Step 2. Develop a standard pipe design model and build a database: A database was built by standardizing the collected plant project data in a consistent format. The user can estimate the typical design man-hour by simply entering the required quantity.

Step 3. Development of correction factors: Country, Duration, and Scale Factors were developed using a machine learning algorithm.

By applying the coefficient to the general design man-hour value calculated in Step 2, we can obtain the design man-hour value that reflects the difference according to the project characteristics.

Step 4. Similar project recommendation function: select similar projects with the user's project based on project characteristic information and present as a reference.

This study is meaningful as it collects historical data and applies statistical analysis and machine learning algorithms in quantitative terms. Using the developed algorithm, project performers, such as EPC Company or Engineering Company, can relatively easily calculate design man-hours using limited information at the beginning of the bid.

\section{LIMITATION AND FUTURE WORKS}

As mentioned above, the scope of this study is basically to predict only the design man-hours corresponding to the piping discipline, and the other disciplines are replaced 
by the method using the ratio of design time between the discipline of commercial data. However, the correlation between project factors (period, etc.) and design time may vary depending on the type of work. Therefore, data on other types of work will be collected in the future, and studies should be conducted to find out the correlation between project types and overall design man-hours as well as each type of work. If data can be collected on a project basis, design man-hour trends by plant type and a customer can also be investigated. Existing regression and correction factors can also be improved.

\section{Funding ACKNOWLEDGEMENT}

The authors acknowledge that this research was sponsored by the Korea Ministry of Trade Industry and Energy (MOTIE/KEIT) through the Technology Innovation Program funding by KEIT for (1) Artificial Intelligence Big-data (AI-BD) Platform for Engineering Decision-support Systems (grant number $=20002806$ ) and (2) Intelligent Project Management Information Systems (i-PMIS) for Engineering Projects (grant number=10077606)..

\section{REFERENCE}

James, D. F. (2005) AACE International Transactions : A Methodology for Estimating Engineering Details.

Marzouk, M., Elkadi. M.(2016) Estimating water treatment plants cost using factor analysis and artificial neural networks. Journal of Cleaner Production 112(2016). http://doi.org/10.1016/j.jclepro.2015.09.015

Sphurti, S., Nagarai, V. (2017) Cost estimation of civil construction projects using machine learning paradigm. International Conference on I-SMAC 2016, pp. 1-5. IEEE (2017). http://doi.org/10.1109/I-SMAC.2017.8058249

Pesko, I., Muscenski. V.(2017) Estimation of Costs and Durations of Construction of Urban Roads Using ANN and SMV.pp.13 (2017).

http://doi.org/10.1155/2017/2450370 